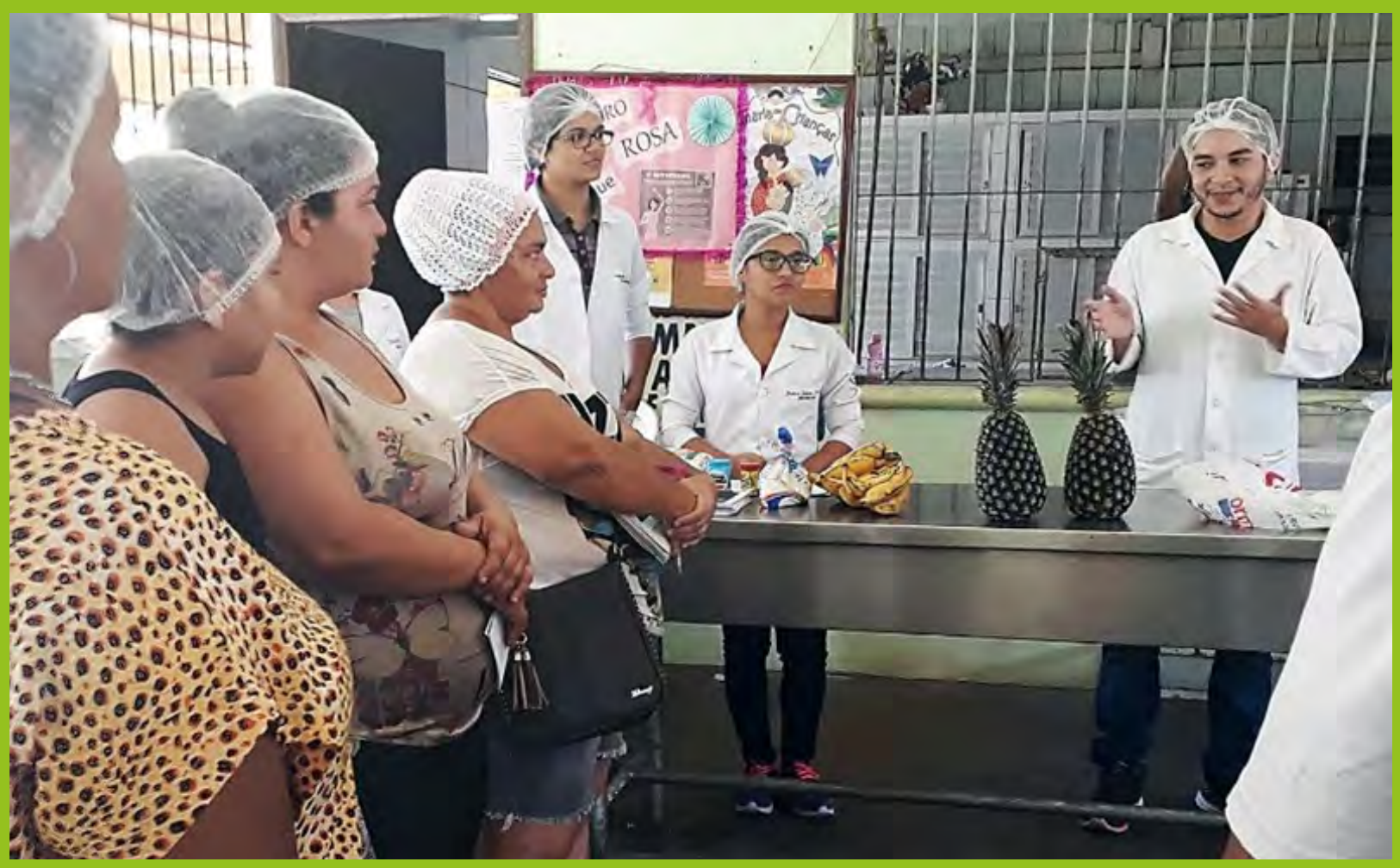

\title{
Extensão universitária como ferramenta de melhoria e desenvolvimento: aspectos higiênico-sanitários de uma Unidade de Alimentação e Nutrição (UAN)
}

Tielly Gleyce dos Reis Nunes - tiellygleycee@gmail.com¹ Luana Maria Meireles Cunha - luana.cunha@itec.ufpa.br Mayra Braga da Silva Lima - mayrabragas|@gmail.com³ Consuelo Lúcia Sousa - sousa@ufpa.br ${ }^{4}$

\section{RESUMO}

0 presente trabalho teve como objetivo avaliar as condições higiênico-sanitárias de uma Unidade de Alimentação e Nutrição - UAN antes e depois de cursos de capacitação. Para avaliar as adequações às Boas Práticas de Fabricação -BPF elaborou-se um checklist que foi aplicado em duas vistorias, antes e após o treinamento. Foram realizadas análises microbiológicas em diversos utensílios e nas mãos do manipulador responsável pela UAN. Realizou-se diversos cursos relacionados às BPF e as técnicas de conservação e armazenamento de alimentos que se iniciaram após a primeira vistoria. No período avaliado, a UAN passou da classificação de "RUIM" para "REGULAR" e algumas análises microbiológicas apresentaram resultados acima do permitido na legislação. Os treinamentos foram considerados excelentes por quase todos os participantes.

1 Engenheira de Alimentos - FEA/UFPA.

2 Graduanda em Engenharia de Alimentos. Bolsista de extensão do Programa do EMAÚS - FEA/UFPA.

3 Graduanda em Engenharia de Alimentos. Bolsista de extensão do Programa do EMAÚS - FEA/UFPA.

4 Professora Titular da faculdade de Engenharia de Alimentos da UFPA. 


\title{
University extension as a tool for improvement and development: hygienic-sanitary aspects of a Food and Nutrition Unit (FNU)
}

\begin{abstract}
This study aimed to evaluate the hygienic and sanitary conditions of a Food and Nutrition Unit - FNU before and after training courses. To evaluate the suitability to Good Manufacturing Practices - GMP, a checklist prepared was applied in two inspections, before and after the training. Microbiological analyses were performed on a kitchenware and in the hands of the handler responsible for the FNU. Several courses related to GMP and the technical conservation and storage of food were undertaken after the first inspection. In the period evaluated, the FNU improved the classification from "BAD" to "REGULAR" and some microbiological analyses showed results above the permitted in the legislation. The trainings were considered excellent by almost all participants.
\end{abstract}

KEYWORDS: good practices; training; food handlers; safe food.

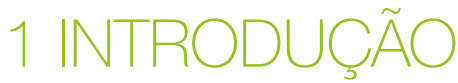

0 acompanhamento das rotinas numa Unidade de Alimentação e Nutrição (UAN) é de fundamental importância na busca por resultados finais satisfatórios, seja do ponto de vista técnico ou econômico. É grande a quantidade de processos a que são submetidos os alimentos em cada etapa da produção de refeições (SOARES et al., 2018). Além de fornecer aos comensais refeições equilibradas, adequadas às suas necessidades nutricionais, as ações realizadas devem garantir a segurança higiênica das preparações, ambiente e de pessoal, a qualidade sensorial da alimentação elaborada, redução e controle de desperdício bem como adequação aos parâmetros de custos determinados previamente (SILVA et al., 2015).

Deve-se ter sempre em mente que uma refeição, além de ser aparentemente saudável e saborosa, precisa ser segura do ponto de vista microbiológico, pois os alimentos destinados ao consumo humano podem estar suscetíveis a diferentes fontes de contaminações por micro-organismos relacionados à manipulação e aos procedimentos inadequados durante o processamento e distribuição (SILVA et al., 2015). A qualidade dos alimentos é uma das condições essenciais para a promoção e manutenção da saúde, e deve ser assegurada pela adoção de medidas preventivas, desde a origem até o consumo, evitando assim a ocorrência de Doenças Transmitidas por Alimentos (DTA) (CUNHA et al., 2012).

A elaboração das refeições, no que diz respeito à qualidade higiênico-sanitária, deve ocorrer de forma a garantir a produção do alimento seguro através, dentre outros, da adoção das Boas Práticas de Fabricação (BPF) - procedimentos que devem ser adotados por serviços de alimentação a fim de garantir a qualidade higiênico-sanitária e a conformidade dos alimentos com a legislação sanitária (SOARES, et al., 2018).

A maioria das pessoas envolvidas com a manipulação de alimentos, carece de conhecimentos relativos aos cuidados higiênico-sanitários, que devem ser seguidos na elaboração dos produtos, desconhecendo também a possibilidade de serem portadores assintomáticos de micro-organismos, o que pode provocar a contaminação dos alimentos, constituindo em risco à saúde pública (PAGOTTO et al., 2018). Segundo dados da Secretaria Estadual de Saúde (BRASIL, 2019) no período de 2009 a 2018, foram registrados 6.809 surtos de DTAs e as principais causas foram conservação e manipulação/preparação inadequadas dos alimentos nas residências.

Para garantir a qualidade higiênico-sanitária dos alimentos, um fator fundamental é o treinamento dos manipuladores de alimentos. Vários estudos demonstram que a educação continuada dos manipuladores contribui para a redução da incidência de DTA (GUARDA et al., 2015; BORGES et al., 2020). Segundo Adane et al. (2018) os treinamentos devem ter abordagens construtivas e inovadoras em educação, serem contínuos e planejados, e com estratégias pedagógicas que induzam a participação de todos para a construção do conhecimento, para promover a incorporação das práticas adequadas, visando melhorar a qualidade higiênica 
dos serviços. Fiorese et al. (2014) destacam a importância do papel dos treinadores nesse processo, que também desenvolvem ações de promoção à saúde, ampliando a consciência sobre a saúde coletiva e encorajando estilos de vida saudáveis.

Tendo em vista as considerações feitas acima, a Faculdade de Engenharia de Alimentos (FEA) da Universidade Federal do Pará (UFPA) através da atividade extensão, ligada ao ensino e pesquisa vem oferecer à comunidade o conhecimento de técnicas voltadas à tecnologia de processamento e conservação de alimentos, além da orientação sobre alimentação segura e saudável, aliados à inclusão social, geração de oportunidade de trabalho e renda contribuindo para sua subsistência e desenvolvimento. Para os docentes e discentes envolvidos nessas atividades, a aplicação dos conhecimentos transmitidos/adquiridos em salas de aula e laboratórios, em atendimento às demandas da comunidade, permite uma atuação profissional com mais responsabilidade social.

0 presente trabalho faz parte de um projeto de extensão da FEA/UFPA e teve como objetivo realizar avaliação das condições higiênico-sanitárias em uma Unidade de Alimentação e Nutrição (UAN) de uma instituição pública localizada na região metropolitana de Belém antes e depois de cursos de capacitação dos manipuladores de alimentos que prestam serviço na instituição.

\section{METODOLOGIA}

\subsection{Aplicação do Checklist}

Foi conduzido um estudo transversal em uma UAN que fornece cerca de 200 refeições por dia, localizada no Município de Belém - Pará. A UAN faz parte de uma instituição pública onde são desenvolvidos cursos e oficinas com o intuito de retirar crianças, adolescentes e adultos das ruas, e dar oportunidade de capacitação às suas famílias, para proporcionar geração de trabalho e renda.

\section{Figura 1 - Unidade de Alimentação e Nutrição (UAN), Belé̉m - PA}

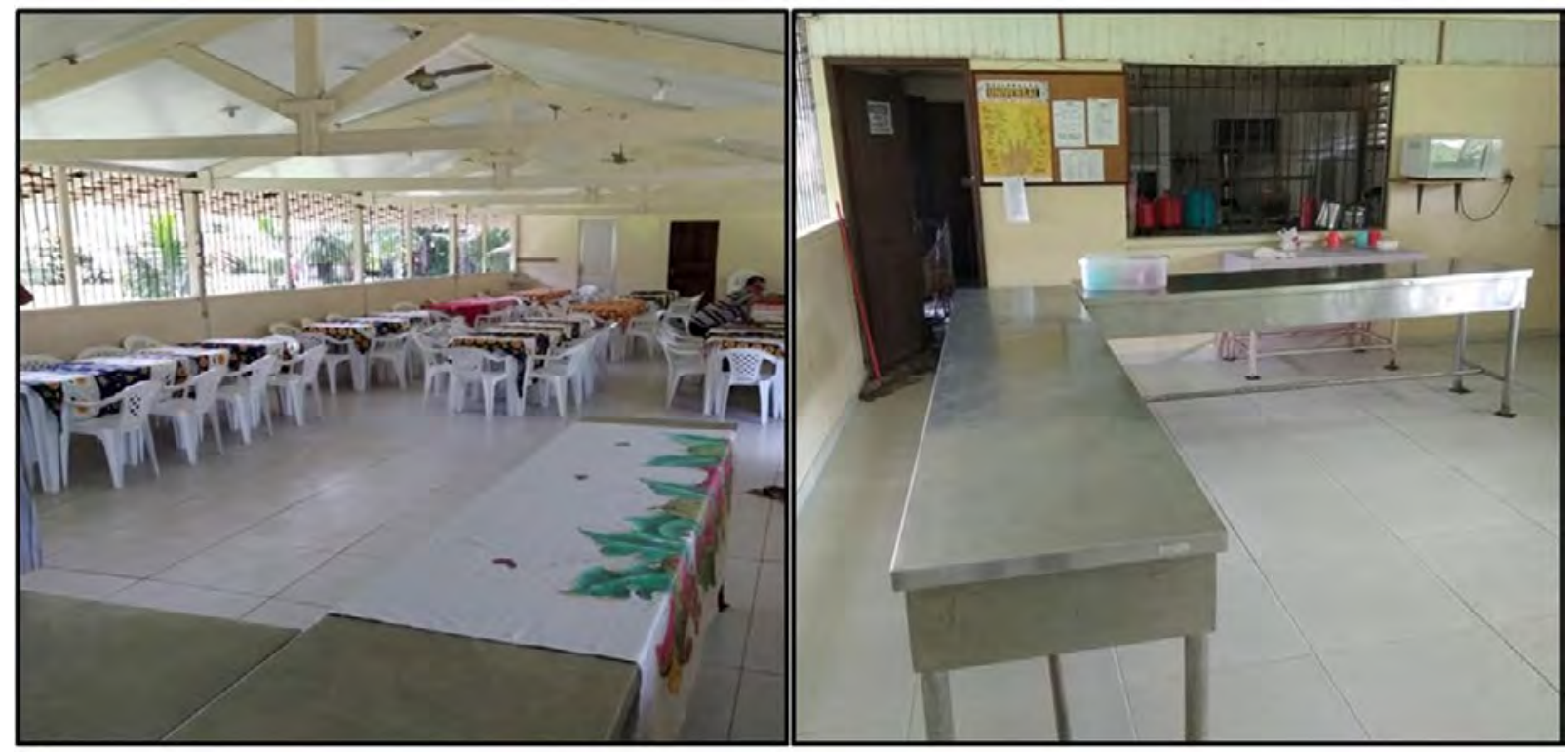

FONTE: Dados do projeto.

Para avaliar o nível de adequação da UAN em relação às BPF foi elaborado um checklist baseado na $\mathrm{RDC}$ n- 216 que dispõe sobre Regulamento Técnico de Boas Práticas para Serviços de Alimentação (BRASIL, 2004), composto por 66 itens de verificação, agrupados em oito blocos de requisitos. 
Tabela 1 - Blocos e número de itens do checklist aplicado na UAN

\begin{tabular}{lc}
\multicolumn{1}{c}{ Blocos } & No itens \\
\hline Bloco 1 - Edificações, Instalações, Equipamentos, Móveis e Utensílios & 18 \\
\hline Bloco 2 - Higienização de Instalações, Equipamentos, Móveis e Utensílios & 7 \\
\hline Bloco 3 - Abastecimento de Água & 2 \\
Bloco 4 - Manejo de Resíduos & 6 \\
Bloco 5 - Manipuladores & 11 \\
Bloco 6 - Matérias-primas, Ingredientes e Embalagens & 3 \\
Bloco 7 - Preparação e Armazenamento do Alimento Preparado & 12 \\
Bloco 8 -Exposição ao Consumo do Alimento Preparado & 7 \\
\hline Total & 66 \\
\hline
\end{tabular}

\section{FONTE: BRASIL, 2004.}

Cada item do checklist foi marcado como: 'Conforme (C)' ou 'Não Conforme (NC)', dependendo se atendia ou não o estabelecido na legislação sanitária vigente. Para cada bloco obteve-se um valor em percentagem, em função da conformidade dos itens. Todos os subitens em conformidades foram somados para se obter a porcentagem geral do estabelecimento. A classificação da UAN foi feita de acordo com o estabelecido na RDC no 216 (BRASIL, 2004): Grupo 1 - BOM (76 a 100\% de atendimento dos itens), Grupo 2 - REGULAR (51 a 75\% de atendimento dos itens) e Grupo 3 - RUIM ( 0 a 50\% de atendimento dos itens). Para a obtenção dos valores em porcentagem para posterior classificação dos blocos e do ambiente, foi utilizada a equação:

$$
\% \text { conformidade }=\left(\frac{\text { Quantidade de itens conformes }}{\text { quantidade de itens totais }}\right) * 100
$$

0 checklist foi aplicado em duas vistorias na UAN, uma no início do projeto e a outra após os cursos de capacitação com o objetivo de comprovar a eficácia dos mesmos no processo de conscientização dos manipuladores que prestam serviço no estabelecimento. Para o preenchimento do checklist foiacompanhada a rotina de trabalho da UAN durante dois dias consecutivos. Durante as vistorias foram repassadas para os responsáveis sugestões de melhoria, sendo entregue o plano de ações corretivas para todas as não conformidades detectadas.

\subsection{Análises Microbiológicas}

Foram realizadas análises microbiológicas em diversos utensílios limpos (copos, pratos e talheres) e nas mãos do manipulador responsável pela UAN, antes do início de suas atividades. Para a coleta das amostras foi utilizada a técnica do swab, adotando-se procedimento proposto pela American Public Health Association, descrito por Evancho et al. (2001). Nos utensílios a coleta foi feita em lotes de cinco unidades de copos, pratos e colheres e o resultado foi expresso como a média das cinco unidades. 
Figura 2 - Coleta das amostras de superfícies (garfo e prato) pela técnica do swab
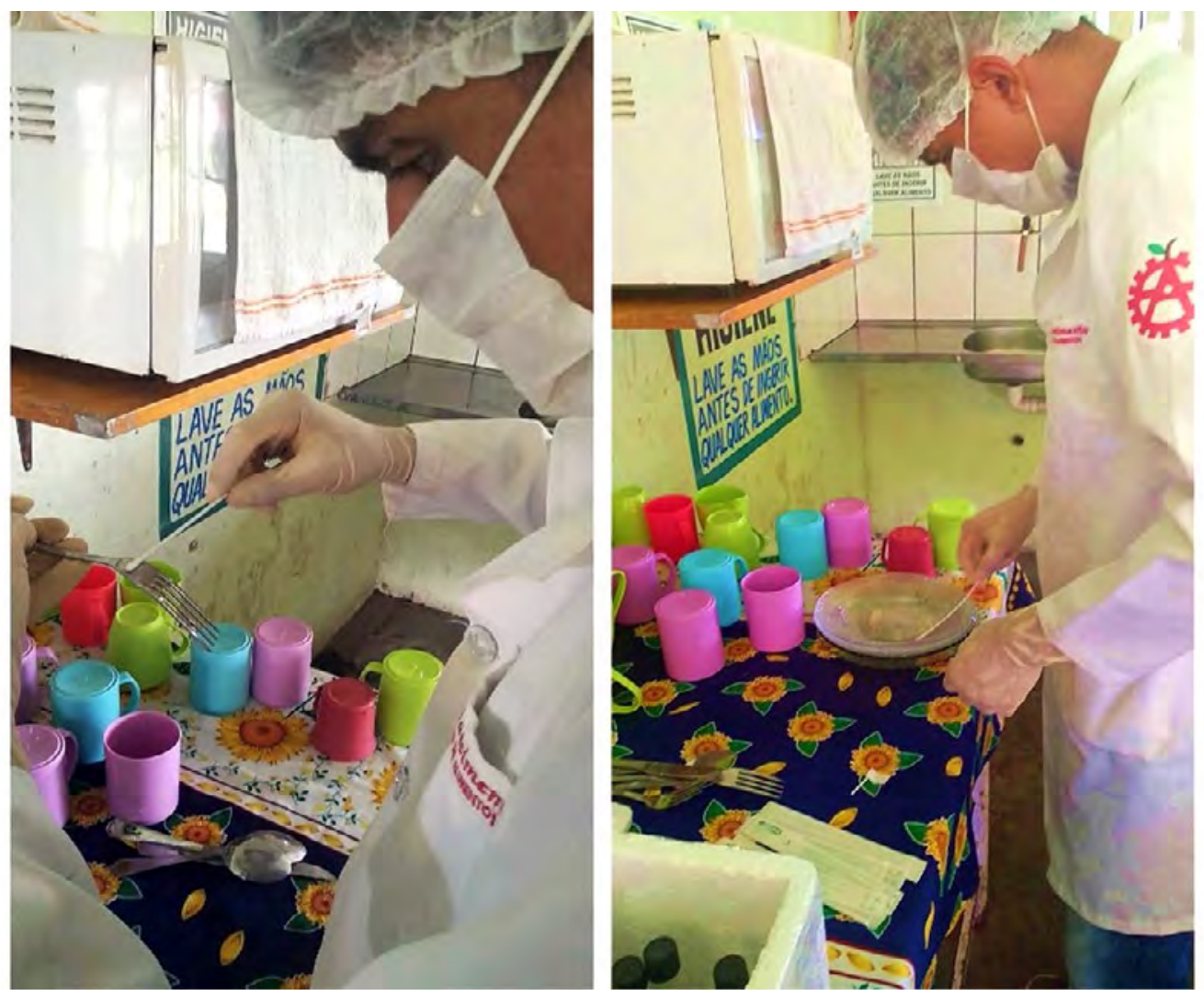

FONTE: Dados do projeto.

Em todas as amostras (utensílios e mãos), foi realizada a contagem de micro-organismos mesófilos aeróbios em Ágar-Padrão para Contagem (PCA), a análise de coliformes a 35으 utilizando a metodologia descritano Compendium of Methods for the Microbiological Examination of Foods (KORNACKlet al., 2015). Todas as análises foram feitas em triplicata e os resultados das contagens, expressos em Unidades Formadoras de Colônia (UFC)/utensílios ou mãos e Número Mais Provável (NMP)/utensílios ou mãos. Ressalta-se que coleta de amostras de superfícies foram realizadas antes do início dos treinamentos, infelizmente veio a pandemia e não se conseguiu fazer uma segunda amostragem.

\subsection{Capacitação dos Manipuladores}

Foram convidados para participar das capacitações a responsável e auxiliares da UAN e também o público-alvo atendidos pela instituição: os adolescentes, os adultos e seus familiares. Os treinamentos iniciaram após a primeira vistoria na UAN e foram realizados algumas vezes na própria UAN ou em salas de aula dentro da própria instituição.

A capacitação consistiu na apresentação teórico ou teórico-prática de informações com foco principal nas BPF, cujos conteúdos abordados foram baseados nas recomendações da legislação sanitária (BRASIL, 2004). A carga horária total da capacitação, 70 horas, foi distribuída em encontros de duas a quatro horas semanais e para cada curso foi oferecida 20 vagas por turma.

Os temas dos cursos foram: noções básicas de microbiologia e doenças transmitidas por alimentos; boas práticas de fabricação; higienização de alimentos; atendimento ao cliente; conservação e armazenamento de alimentos; processamento mínimo de hortaliças e frutas; rotulagem de alimentos.

Os cursos foram abordados por meio da apresentação de slides, aplicação de demonstrações, dinâmicas e simulações de situações características da produção de alimentos. Ao longo da apresentação, a participação dos manipuladores foi estimulada por intermédio de perguntas dirigidas. Como método facilitador do aprendizado foram utilizadas figuras ilustrativas e fotos das condições reais dos locais de processamento, com o intuito de promover a construção de conhecimento e motivar a mudança comportamental dos participantes, através da conscientização de cada um, quanto ao seu papel no processo produtivo.

Foi elaborado um manual técnico para manipulador de alimentos com uma linguagem acessível e bem ilustrativo que foi impresso e distribuído durante a capacitação para todos os participantes. Também foram 
distribuídos folhetos explicativos contendo as informações tratadas em cada curso com abordagem clara e por meio de figuras.

Os ministrantes dos cursos e responsáveis pela elaboração de todo material didático, foram os alunos da graduação de Engenharia de Alimentos da UFPA participantes do projeto de extensão sob a supervisão dos professores da mesma instituição.

Após a concretização do treinamento, houve uma nova aplicação do checklist na UAN para verificar se o aprendizado teve influência na mudança de comportamento dos manipuladores.

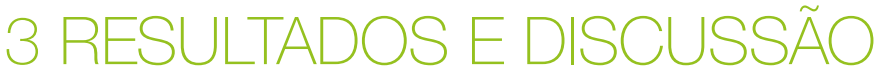

\subsection{Diagnostico Checklist}

O resultado da avaliação do checklist da primeira vistoria na UAN foi classificado como "RUIM", visto que atendeu abaixo de $50 \%$ das conformidades, após o período de treinamentos e plano de ações corretivas, o segundo checklist foi realizado e atendeu $65,15 \%$ de conformidades, sendo foi classificado como um estabelecimento "REGULAR". 0 resultado demonstra que pequenas mudanças de hábitos e a aplicação de conceitos básicos sobre BPF, higienização pessoal, segurança alimentar e microbiologia de alimentos conseguiram surtir melhorias expressivas na qualidade das refeições produzidas pela UAN. Rebouças et al. (2021) ao analisarem 13 estabelecimentos de serviços de alimentação do município de Unaí, Minas Gerais, relatam no diagnóstico inicial a média geral de conformidades em $57 \%$ e, após as intervenções e treinamento o diagnóstico apresentou o resultado de conformidades em $79 \%$, sendo classificado como bom.

Entre as principais não conformidades detectadas na primeira vistoria, podem ser destacadas a inexistência de separação, por meios físicos, que evitassem a contaminação cruzada entre as atividades de pré-preparo, preparo e higienização dos alimentos; a presença de pragas no ambiente; o espaço limitado da cozinha que dificultava o acondicionamento dos alimentos em armários e prateleiras; os manipuladores portando adornos; utensílios expostos a contaminação externa; falta de cartazes com orientação sobre a correta higienização das mãos e dos alimentos; o manejo de resíduos acontecendo de maneira irregular pela falta de recipientes com acionamento automático.

Tabela 2 - Diagnóstico das condições higiênico-sanitárias da UAN antes e após os cursos de boas práticas de fabricação no município de Belém - Pará

\begin{tabular}{lllllll}
\hline \multicolumn{3}{c}{ PRIMEIRA VISTORIA } & \multicolumn{3}{c}{ SEGUNDA VISTORIA } \\
\hline Blocos & C (\%) & NC (\%) & Avaliação & C (\%) & NC (\%) & Avaliação \\
\hline 1 & 27,78 & 72,22 & Ruim & 61,11 & 38,89 & Regular \\
\hline 2 & 28,57 & 71,43 & Ruim & 71,43 & 28,57 & Regular \\
\hline 3 & 50,00 & 50,00 & Ruim & 100,00 & 0,00 & Bom \\
\hline 4 & 16,67 & 83,33 & Ruim & 66,67 & 33,33 & Regular \\
\hline 5 & 36,36 & 63,64 & Ruim & 72,73 & 27,27 & Regular \\
\hline 6 & 0,00 & 100,00 & Ruim & 50,00 & 50,00 & Ruim \\
\hline 7 & 33,33 & 66,67 & Ruim & 75,00 & 25,00 & Regular \\
\hline 8 & 14,29 & 85,71 & Ruim & 57,14 & 42,86 & Regular \\
\hline
\end{tabular}

Legenda: 1. Edificação, instalações, etc; 2. Higienização 3. Água; 4. Manejo dos resíduos; 5. Manipuladores; 6. Matérias-primas, Armazenamento dos ingredientes e embalagens; 7. Preparação e armazenamento; 8. Exposição ao consumo. C- conforme, NC - não conforme.

FONTE: Dados do projeto.

Dentre as principais dificuldades encontradas na eliminação das não conformidades, destaca-se a não adequação do Bloco 1 que corresponde ao piso, paredes e teto, além do ajuste no layout, devido aos altos custos financeiros envolvidos. Para as adequações das não conformidades foi dada prioridade para as ações mais simples de serem adequadas e/ou às mais críticas, de forma a não comprometer a rotina da UAN. Os problemas foram gradativamente sendo resolvidos com os cursos de capacitação, mudança de hábitos dos manipuladores e acompanhamento técnico frequente, conforme observado na vistoria subsequente, com o incremento dos itens conformes. 
Os 8 blocos foram classificados como "RUIM" durante a primeira vistoria e posteriormente, através dos cursos de capacitação, mudanças de hábitos dos manipuladores e melhorias estruturais na UAN, na segunda vistoria os blocos foram classificados como "REGULAR" ou "BOM", o que indica uma melhora gradual. 0 bloco sobre os manipuladores apresentou resultados acima de $70 \%$ de itens conformes e em consequência os blocos sobre higienização e preparação de alimentos demonstraram resultados proporcionais, o que demonstra que os cursos relacionados a BPF e higiene pessoal foram essenciais para que o manipulador exerça de forma adequada suas funções pois essas mudanças de rotina são provenientes dos bons hábitos dos mesmos.

Estudo realizado por Maciel et al. (2017) na Universidade Federal de Sergipe (UFS), onde estão localizadas duas UANs apresentou resultados que demonstram a necessidade contínua de treinamentos que foquem nas BPF. Uma UAN apresentou apenas $17 \%$ de itens conformes enquanto a outra $39 \%$, ambas foram classificadas como "RUIM" por apresentarem menos de $50 \%$ de adequações. Segundo Borges et al. (2020) o fator humano é um elemento central na aplicação e manutenção das BPF, pois é também uma das vias mais frequentes de transmissão de micro-organismos que pode ocorrer durante a manipulação dos alimentos. Portanto, todas as pessoas que participam da manipulação dos alimentos devem ter o conhecimento sobre a importância de fornecer um alimento seguro aos indivíduos.

Pagotto et al. (2018) ressaltam que a higiene pessoal bem como os comportamentos assumidos durante a manipulação dos alimentos devem ser frequentemente supervisionados e abordados em capacitações contínuas para manipuladores de alimentos, o que corrobora com os resultados detectados no presente estudo, pois, após os treinamento em Boas Práticas de Fabricação e higiene pessoal e dos Alimentos, oferecidos aos colaboradores da UAN, constatou-se que a porcentagem de itens conformes com as diretrizes da Legislação sanitária aumentou consideravelmente.

\subsection{Análises Microbiológicas}

Foi verificado que todas as superfícies analisadas (mãos e utensílios) da UAN, apresentaram elevados índices de contaminação microbiológica (Tabela 3), o que sugere a necessidade de medidas efetivas de controle. Superfícies que entram em contato com o alimento podem se tornar focos de contaminação, principalmente quando não forem bem higienizadas (SILVA et al., 2015; SCHUMANN et al., 2017).

Tabela 3 - Quantificação de bactérias aeróbias mesófilas, coliformes a 35ㄷ e $45^{\circ} \mathrm{C}$ em copos, pratos, talheres e mãos de manipuladores de alimentos de uma UAN no município de Belém do Pará

\begin{tabular}{|c|c|c|c|}
\hline \multirow{2}{*}{ Blocos } & \multirow{2}{*}{$\begin{array}{l}\text { Bactérias Aeróbias Mesófflas } \\
\text { (UFC/utensillio ou mãos) }\end{array}$} & Coliformes $35^{\circ} \mathrm{C}$ & Coliformes $45^{\circ} \mathrm{C}$ \\
\hline & & \multicolumn{2}{|c|}{ (NMP/utensilio ou mãos) } \\
\hline *Copos & $8,1 \times 10^{5}$ & $9,9 \times 10^{3}$ & $9,9 \times 10^{3}$ \\
\hline *Pratos & $3,6 \times 10^{3}$ & $1,6 \times 10^{2}$ & $3,1 \times 10^{1}$ \\
\hline *Talheres & $2,1 \times 10^{4}$ & $2,4 \times 10^{3}$ & $1,4 \times 10^{3}$ \\
\hline Mãos & $2,3 \times 10^{4}$ & $8,4 \times 10^{2}$ & $8,3 \times 10^{1}$ \\
\hline
\end{tabular}

Legenda: * lotes de cinco unidades, UFC - unidades formadoras de colônias, NMP - número mais provável.

FONTE: Elaborado pelos autores.

No Brasil ainda não existe uma legislação que estabeleça parâmetros microbiológicos para superfícies de utensílios utilizados no processamento de alimentos, bem como para as mãos de manipuladores. Entretanto a American Public Health Association (APHA) preconiza para superfícies de utensílios valores máximos de 100UFC/utensílio para as contagens de aeróbios mesófilos e ausência de coliformes a $45^{\circ} \mathrm{C}$ (BARBOSA et al., 2011). Para as mãos, Andrade (2008) estabeleceu contagem máxima de $10^{2}$ UFC/mão para mesófilos aeróbios e coliformes totais. Todas as amostras analisadas estavam fora das recomendações.

Os copos foram os que tiveram o maior nível de contaminação, o que pode ser justificado pelo fato de ficarem expostos ao meio ambiente em condições propícias para contaminação. A presença de micro-organismos em utensílios e mãos de manipuladores de alimentos já foi relatada por diversos autores. Ponath 
et al. (2016) ao avaliaram a higienização das mãos de manipuladores de alimentos encontraram contagem de mesófilos de até $1,9 \times 10^{5} \mathrm{UFC} / \mathrm{mão}$. Da mesma forma Soares et al. (2018) quando analisaram as condições higiênico-sanitárias de uma UAN observaram que os aspectos que mais contribuíram para os baixos índices de conformidades estavam relacionados à higienização inadequada dos utensílios e mãos dos manipuladores. Resultados preocupantes também foram evidenciados por Santos et al. (2020), em uma UAN de um hospital público, onde detectaram amostras de superfícies, equipamentos, utensílios e mãos com contagens acima de $50 \mathrm{UFC} / \mathrm{cm}^{2}$ de mesófilos, demonstrando condições higiênicas insatisfatórias, representando riscos à saúde dos consumidores e/ou pacientes.

\subsection{Capacitação dos Manipuladores}

0 primeiro passo para a melhoria das não conformidades são cursos que visem a capacitação e conscientização sobre a importância das BPF e como garantir a segurança dos alimentos. Neste sentido, foram realizados cursos com este propósito, com as temáticas: Boas Práticas de Fabricação, Higienização de alimentos, Noções de Microbiologia, Armazenamento e Conservação dos alimentos e Processamento mínimo de frutas e hortaliças evidenciado (Figura 3.)

\section{Figura 3 - Capacitação sobre BPF e técnicas de produção, conservação e armazenamento de} alimentos
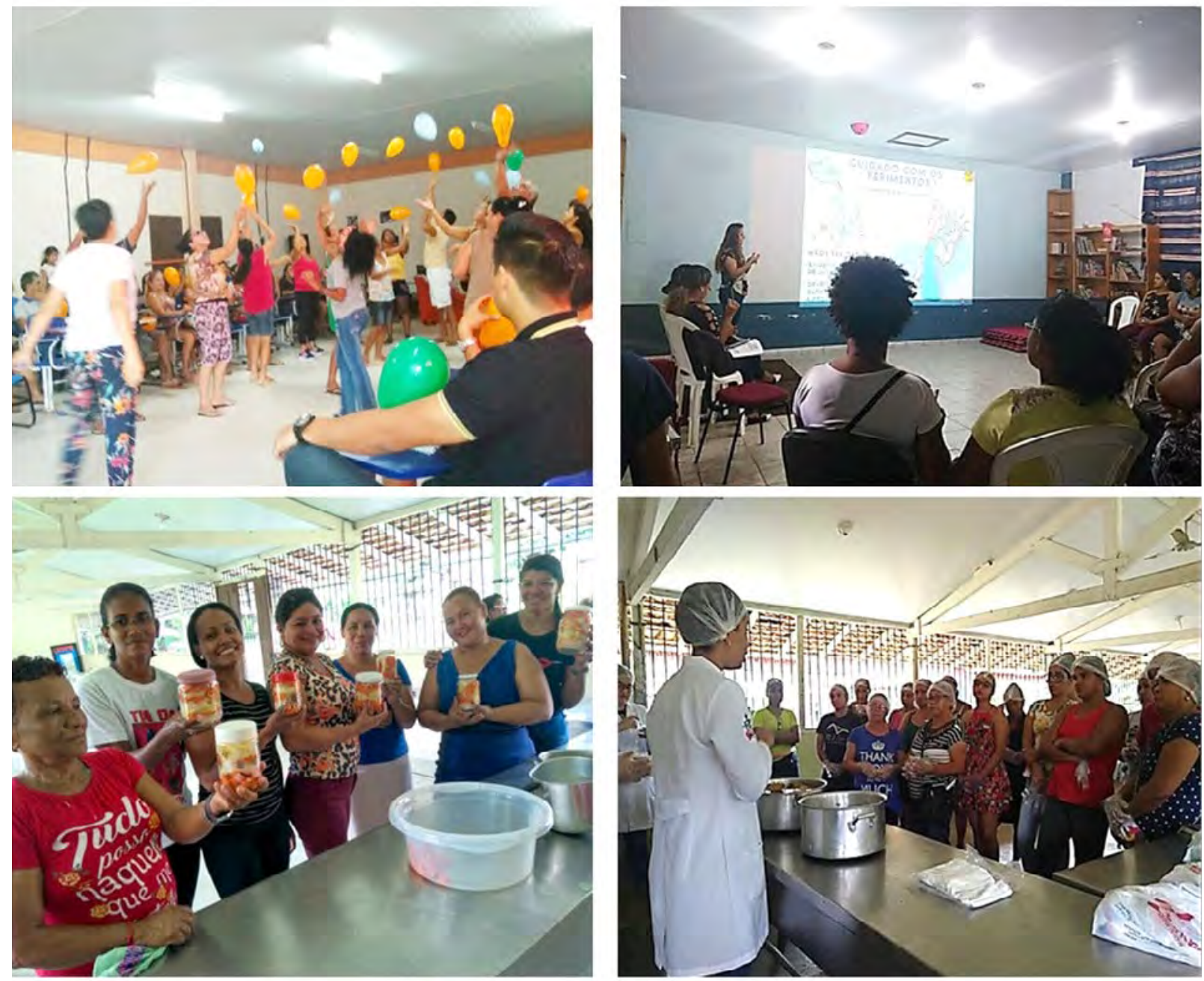

FONTE: Dados do projeto.

Os cursos de capacitação aconteceram durante um período aproximado de 8 meses, sendo ofertados 2 cursos por mês, com número variável de participantes. Os cursos aconteceram em diferentes períodos, pois foi necessário se adequar a rotina e a disponibilidade dos participantes. 
Tabela 4 - Cursos ministrados na UAN, carga horária e número de participantes

\begin{tabular}{|c|c|c|}
\hline Cursos & Carga Horária & № participantes \\
\hline Noções Básicas de Microbiologia & 8 & 21 \\
\hline Doenças Transmitidas por Alimentos (DTAs) & 6 & 19 \\
\hline Boas Práticas de Fabricação & 12 & 25 \\
\hline Higienização de Alimentos & 8 & 25 \\
\hline Atendimento ao Cliente & 10 & 20 \\
\hline Conservação e Armazenamento de Alimentos & 8 & 23 \\
\hline Processamento Mínimo de Frutas e Hortaliças & 8 & 25 \\
\hline Rotulagem dos Alimentos & 10 & 25 \\
\hline Total & 70 & 183 \\
\hline
\end{tabular}

FONTE: Dados do Projeto.

Quanto ao perfil dos participantes, $80 \%$ eram do sexo feminino, com idade superior a 25 anos, escolaridade máxima ensino médio completo, sendo em sua maioria manipuladores voluntários da UAN e donas de casa que tem seus filhos atendidos na instituição.

Os participantes, em sua maioria, relataram nunca terem participado de treinamentos em Boas Práticas de Fabricação e de maneira geral houve grande receptividade, com questionamentos frequentes desde questões simples, como: "qual a maneira correta de higienizar as mãos?", "como se deve higienizar os alimentos?" até as mais complexas como: "quais os principais micro-organismos que causam surtos alimentares?". Essa abertura foi de vital importância para maior fixação dos conceitos explicitados e na melhoria gradativa da rotina da UAN.

\section{Figura 4 - Capacitação sobre técnicas de higienização de frutas}

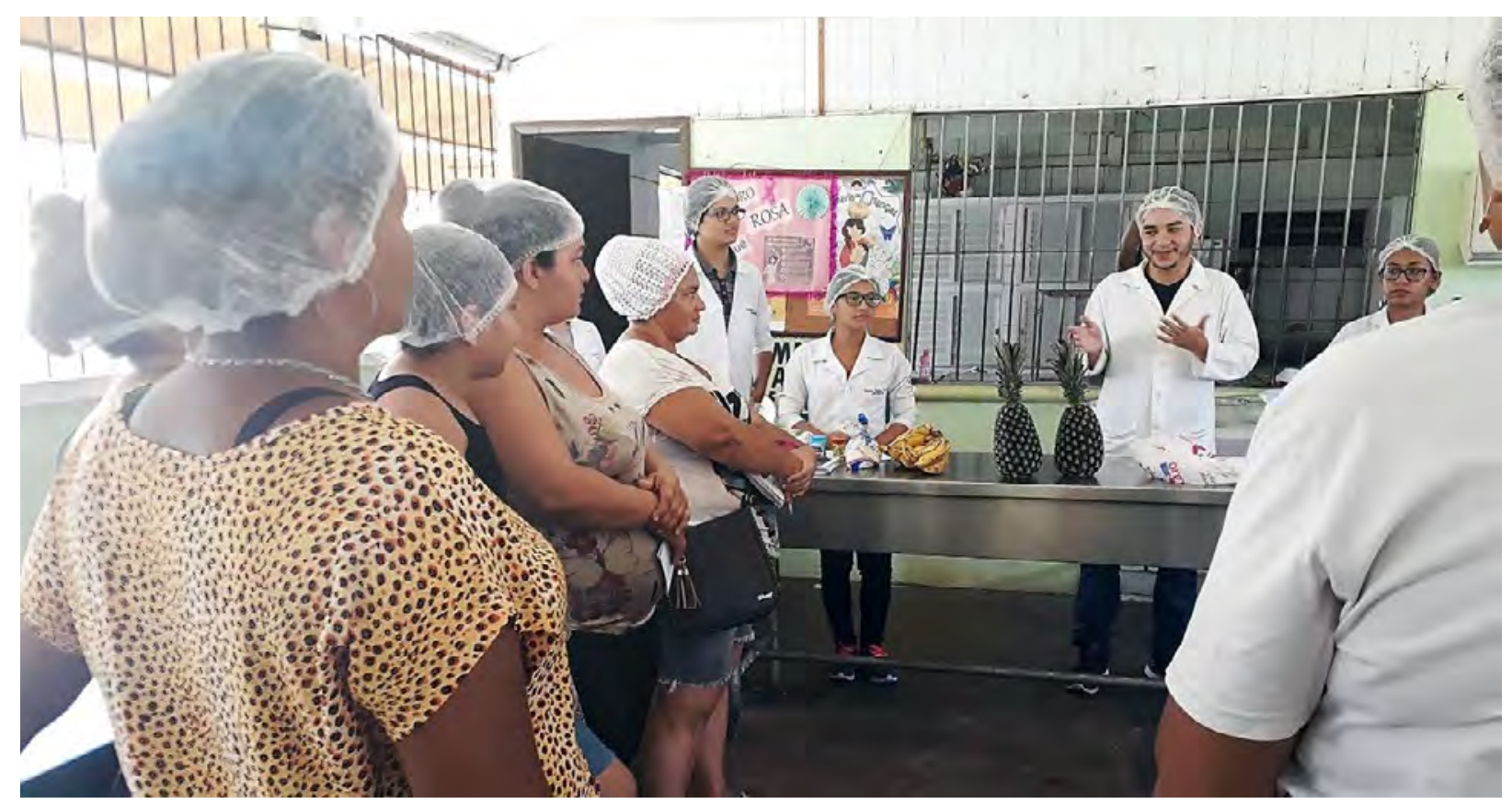

FONTE: Dados do projeto.

Falhas quanto ao entendimento e conhecimento sobre cuidados com os alimentos podem diminuir o nível de consciência sobre manipulação adequada e culminar em uma falsa ideia de segurança (SANI; SIOW, 2014). De acordo com Gomes et al. (2014) para alcançar a efetividade de um treinamento é necessário que o manipulador compreenda as razões para a adoção de comportamentos que promovem mudanças. Vários 
estudos relatam que a prática de treinamentos de higiene frequente em estabelecimentos que preparam e/ ou comercializam alimentos são eficazes na melhoria das condições de limpeza e organização do ambiente (BORGES et al., 2020; LOPES et al., 2020).

Neste sentido, constata-se que a capacitação realizada no presente estudo foi bem-sucedida à medida que provocou alteração de comportamento e adoção de novos hábitos na prática dos manipuladores. Lopes et al. (2020) ressaltam que a capacitação de manipuladores deve ocorrer de forma contínua e de maneira que estimule a participação e compreensão dos conceitos transmitidos. Para isto, devem ser elaborados programas de treinamentos, potencializando a frequência de oferecimento, proporcionando assim a formação educacional efetiva dos colaboradores em segurança alimentar (GOMES et al., 2014).

As mudanças provenientes deste projeto de extensão universitária abrangem as diversas esferas do conhecimento, desde os manipuladores de alimentos aos estudantes que auxiliaram na construção do conhecimento técnico em conjunto com seus professores orientadores. Desta forma, ressalta-se a importância que este projeto teve na formação acadêmica dos alunos que o executaram, por estarem envolvidos diretamente no processo de aprendizagem, aprendendo e ensinando ocorre uma melhora significativa no seu nível de formação, contribuindo para uma vivência mais realista muitas vezes omitida em sala de aula, com isso tornam-se mais aptos para entender e solucionar os problemas da vida profissional, além de que possa gerar grandes benefícios para a comunidade.

Posteriormente, ao final dos cursos de capacitação, a meta era realizar análises microbiológicas comparativas entre a primeira vistoria e a segunda vistoria para demonstrar que as mudanças de hábitos surtiram os efeitos esperados no campo microbiológico, entretanto o ano de 2020 foi bastante conturbado com o advento da pandemia do Covid-19 e por isso algumas etapas do projeto não foram finalizadas.

\section{CONSIDERAÇÕES FINAIS}

0 presente estudo demonstrou a eficácia da extensão universitária no processo de transmissão de conhecimento sobreas Boas Práticas deFabricação numarotina diferente do ambiente industrial eacadêmico, pois ocorreu a mudança de hábitos dos manipuladores de alimentos que prestam serviços na UAN e isso surtiu efeito direto nos aspectos higiênico-sanitários, pois antes dos cursos baseadas nas BPFs o refeitório da UAN foi classificado como "RUIM", após a realização dos mesmos a classificação evoluiu para "REGULAR". A manutenção dessa ferramenta de gestão dependerá de ações contínuas para as melhorias e capacitação dos manipuladores a fim de garantir a segurança alimentar por meio das mudanças implementadas.

\section{REFERENNCIAS}

ADANE, Metadel et al. Food hygiene and safety measures among food handlers in street food shops and food establishments of Dessie town, Ethiopia: A community-based cross-sectional study. Plos One, Ethiopia, v.13, n. 5, p. 1-13, 2018. D0I: https://doi.org/10.1371/journal.pone.0196919

ANDRADE, Nélio José de. Higiene na indústria de alimentos: avaliação e controle da adesão e formação de biofilmes bacterianos. São Paulo: Editora Varela, 2008.

BARBOSA, Lídia Granato et al. Determinação de coliformes e aplicação de check list em uma unidade de alimentação pública do Estado de Minas Gerais. Higiene Alimentar, São Paulo, v. 25, n. 196/197, p. 38-41, 2011.

BORGES, Patrícia de Jesus et al. Avaliação de treinamento com manipuladores de alimentos após ocorrência de surto de toxinfecção alimentar em restaurante universitário. Univap, São José dos Campos, v. 26, n. 52, p. 8090, 2020. DOI: http://dx.doi.org/10.18066/revistaunivap.v26i52.2298

BRASIL, Ministério da Saúde. Agência Nacional de Vigilância Sanitária. Resolução RDC no 216, de 15 de setembro de 2004. Dispõe sobre Regulamento Técnico de Boas Práticas para Serviços de Alimentação. Brasília, Diário Oficial da União. Disponível em: https://bvsms.saude.gov.br/bvs/saudelegis/anvisa/2004/ res0216 15 09 2004.html. Acesso em 5 jan. de 2021.

BRASIL. Secretaria Estadual de Saúde. Vigilância epidemiológica das doenças transmitidas por alimentos. Secretaria-Executiva de Vigilância em Saúde, 2019. Disponível em: https://portalarquivos2.saude.gov.br/ images/pdf/2018/>. Acesso em: 13 dez. 2019. 
CUNHA, Fernanda Maria Farias et al. Desafios da gestão da segurança dos alimentos em unidades de alimentação e nutrição no Brasil: uma revisão. Revista Contextos, São Paulo, v. 1, n. 2, p. 4-14, 2012.

EVANCHO, George M. et al. Microbiological Monitoring of the Food Processing Environment. In: DOWNES, Frances Pouch, ITO, Keith. Compendium of methods for the microbiological examination of foods. American Public Health Association (APHA), Washington, 4a ed., p. 676, 2001.

FIORESE, Mônica Lady et al. Treinamento dos manipuladores de alimentos e responsabilidade sobre a saúde pública dos comensais. Revista Extendere, Mossoró, v. 2, n. 2, p. 28-44, 2014.

GOMES, C. C. B. et al. Training of Food Handlers in a Hotel: Tool for Promotion of the Food Safety. Journal of Food Safety, v. 34, n. 3, p. 218-223, 2014. D0I: https://doi.org/10.1111/jfs.12116

GUARDA, Vera Lúcia de Miranda et al. A importância da qualificação de manipuladores de alimentos: estudo de caso na produção de salgados na cidade de Mariana/MG. Caminho Aberto: Revista de Extensão do IFSC, Florianópolis, v. 2, n. 3, p. 14-22, 2015.

KORNACKI, Jeffrey et al. Enterobacteriaceae, coliforms, and Escherichia coli as quality and safety indications. In: Salfinger, Y.; Tortorello, M. L. (eds.), Compendium of Methods for the Microbiological Examination of foods, 5a ed. Washington: American Public Health Association (APHA), cap. 9, p. 103-120, 2015.

LOPES, Larissa Chivanski et al. Relato de experiências do programa de extensão da universidade do extremo sul catarinense através do "curso de culinária profissional e segurança alimentar". Revista de Extensão da UNESC Criciúma, v. 1, n. 1, p. 78-84, 2019. D0I: http://dx.doi.org/10.18616/re.v4i1

MACIEL, Samea Elaine Santos et al. Unidades de alimentação e nutrição: Aplicação de check - list e avaliação microbiológica. Revista Brasileira de Higiene e Sanidade Animal. Fortaleza, v. 11, n. 4, p. 399- 415, 2017.

PAGOTTO, Hiara Zanoni et al. Nível de conhecimento, atitudes e práticas dos manipuladores de alimentos em serviços de alimentação. Demetra: Alimentação, Nutrição \& Saúde, Rio de Janeiro, v. 13, n. 1, p. 293-305, 2018. DOI: https://doi.org/10.12957/demetra.2018.30528

PONATH, Fabiane Seidler et al. Avaliação da higienização das mãos de manipuladores de alimentos do Município de Ji-Paraná, Estado de Rondônia, Brasil. Revista Pan-Amazônica de Saude, Ananindeua, v.7, n.1, p. 63- 69, 2016. DOI: http://dx.doi.org/10.5123/S2176-62232016000100008

REBOUÇAS, Kaira Cristina Ferreira Araújo et al. Avaliação das Condições Higiênico-Sanitárias e Físico-Estruturais em Unidades de Alimentação e Nutrição de um Estado do Nordeste Brasileiro. Ensaios e Ciência, Londrina, v. 25, n. 1, p. 66-77, 2021. D0l: https://doi.org/10.17921/1415-6938.2021v25n1p66-71

SANI, Norrakiah Abdullah; SIOW, Oi Nee. Knowledge, attitudes and practices of food handlers on food safety in food service operations at the Universiti Kebangsaan, Malaysia. Food Control, v. 37, n. 1, p. 210-217, 2014. D0I: https://doi.org/10.1016/j.foodcont.2013.09.036

SANTOS, Amanda de Oliveira dos et al. Avaliação da contaminação de equipamentos, utensílios e mãos de manipuladores de um serviço de nutrição e dietética. Archives of Veterinary Science, Curitiba, v. 25, n. 3, p. 74-84, 2020. DOI: http://dx.doi.org/10.5380/avs.v25i3

SCHUMANN, Adriane Cristina et al. Avaliação microbiológica de mãos dos manipuladores de alimentos e de utensílios de cozinha do serviço de nutrição de um hospital do norte do estado do rio grande do sul. Perspectiva, Erechim. v. 41, n. 153, p. 07-17, 2017.

SILVA, Ana Alice da et al. Manipulação de alimentos em uma cozinha hospitalar: ênfase na segurança dos alimentos. Revista Caderno Pedagógico, Lajeado, v. 12, n. 1, p. 111-123, 2015.

SOARES, Daniele da Silva Bastos et al. Boas Práticas em Unidades de Alimentação e Nutrição Escolares de um município do estado do Rio de Janeiro - Brasil. Ciência e saúde coletiva, Rio de Janeiro, v. 23, n. 12, p. 40774083, 2018. DOI: https://doi.org/10.1590/1413-812320182312.23992016 